\title{
BMJ Open Respiratory health status and its predictors: a cross-sectional study among coal-based sponge iron plant workers in Barjora, India
}

\author{
Kaushik Chattopadhyay, ${ }^{1}$ Chaitali Chattopadhyay, ${ }^{2}$ Eva Kaltenthaler ${ }^{3}$
}

To cite: Chattopadhyay K, Chattopadhyay $\mathrm{C}$, Kaltenthaler E. Respiratory health status and its predictors: a cross-sectional study among coal-based sponge iron plant workers in Barjora, India. BMJ Open 2015;5:e007084. doi:10.1136/bmjopen-2014007084

- Prepublication history for this paper is available online. To view these files please visit the journal online (http://dx.doi.org/10.1136/ bmjopen-2014-007084).

Received 1 November 2014 Revised 5 February 2015 Accepted 7 February 2015

CrossMark

\footnotetext{
${ }^{1}$ Faculty of Epidemiology and Population Health, London School of Hygiene and Tropical Medicine, London, UK

${ }^{2}$ Monitoring and Evaluation, United Nations Office for Project Services, Geneva, Switzerland

${ }^{3}$ Health Economics and Decision Science, School of Health and Related Research, The University of Sheffield, Sheffield, UK
}

Correspondence to Dr Kaushik Chattopadhyay; kaushik.chattopadhyay@ Ishtm.ac.uk

\section{ABSTRACT}

Objectives: During the past decade, coal-based sponge iron plants, a highly polluted industry, have grown rapidly in Barjora, India. The toxic effects of particulate matters and gaseous pollutants include various respiratory diseases. Understanding workers' perception of respiratory health is essential in people-centred healthcare. The aim of the study was to assess their respiratory health status and to determine its predictors. Design: Cross-sectional study.

Setting: Coal-based sponge iron plants in Barjora, India. Participants: 258 coal-based sponge iron plant workers.

Primary outcome measure: Respiratory health status was measured using the St. George's respiratory questionnaire (SGRQ) total score. 100 and 0 represent the worst and best possible respiratory health status, respectively.

Statistical analyses: The two-part model (frequency (any worse respiratory health status) and severity (amount of worse respiratory health status)) was developed for the score, as the data were positively skewed with many zeros.

Results: The mean (SD) SGRQ total score was 7.7 (14.5), the median (IQR) was 0.9 (9.0), and the observed range was $0-86.6$. The best possible $S G R Q$ total score was reported by $46.9 \%$ of workers. Independent predictors of worse respiratory health status were cleaner domestic cooking fuel (coefficient $-0.76,95 \% \mathrm{Cl}-1.46$ to $-0.06, p=0.034$ ) and personal history of any respiratory disease $(1.76,1.04$ to $2.47, p<0.001)$ in case of frequency; and family history of any respiratory disease $(0.43,0.02$ to $0.83, p=0.039)$ and personal history $(1.19,0.83$ to $1.54, p<0.001)$ in case of severity. Conclusions: Less than half of the coal-based sponge iron plant workers in Barjora have the best possible respiratory health status. The predictors of worse respiratory health status were identified. The study findings could be taken into consideration in future interventional studies aimed at improving the respiratory health status of these workers.

\section{INTRODUCTION}

Sponge iron or direct-reduced iron is a transitional material used in the production of

\section{Strengths and limitations of this study}

- This is the first study to explore respiratory health status of coal-based sponge iron plant workers.

- Respiratory health status measurement is subjective to participants, and thus a valid and reliable tool, the St. George's respiratory questionnaire (SGRQ), was used.

- The response rate was $100 \%$. Missing data could lead to bias, but it was extremely low in this study.

- Participants who were absent from work on the dates of the survey were excluded, and this absence from work could be due to poor respiratory health status, which could have underestimated the worse respiratory health status.

- As this was a cross-sectional study, it was not possible to determine the causal association between different variables and respiratory health status.

steel. Either coal or natural gas is used in sponge iron production. In India, non-coking coal is easily available. Thus, the sector depends mostly on coal-based sponge iron and nearly $80 \%$ of the total coal-based sponge iron plants are located in India. ${ }^{1}$ About $60 \%$ of this production comes from small-scale industries in the unorganised sector with poor pollution control facilities. ${ }^{1}$ During the past decade, these sponge iron plants have rapidly grown in the Barjora block of Bankura district, a deprived district in West Bengal. $^{2}$ These factories are categorised as red industries (highly polluted industries) and the major pollutants are of three types: solid waste heavy metals (cadmium, chromium, lead, mercury and nickel); particulate matters (suspended particulate matter and respirable particulate matter) and gaseous pollutants (oxides of sulfur and nitrogen, and hydrocarbons). ${ }^{1-4}$ The toxic effects of solid waste heavy metals are varied and often take several years to manifest. However, the toxic effects of particulate matters and gaseous 
pollutants are often rapid and include respiratory diseases (cough, phlegm, bronchitis, asthma and allergy). ${ }^{1-4}$ The importance of prevention and treatment of these ailments is well acknowledged; however, understanding workers' perception of respiratory health is also essential in people-centred healthcare. ${ }^{5}$ Respiratory health status is a complex and multidimensional concept of the wellbeing of a person and their perception of respiratory health. Respiratory health status is one of the essential aspects of respiratory health, which is embedded in the physical, mental, social and cultural context. ${ }^{6} 7$ Poor respiratory health status places a burden on the individual, family, community and health services, and thus respiratory health status is of major public health importance. ${ }^{6}{ }^{7}$ Research has been conducted to explore the respiratory health status of the general population and other industrial workers in various countries, ${ }^{8-10}$ but none among coal-based sponge iron plant workers. The aim of the study was to assess their respiratory health status and to determine factors that independently predict their respiratory health status. Knowledge of factors associated with the respiratory health status of these workers would provide valuable information about strategies that professionals and providers of healthcare can address to improve their respiratory health status.

\section{METHODS}

\section{Study design, participants, area and inclusion/exclusion} criteria

A cross-sectional study was conducted among coal-based sponge iron plant workers in Barjora block (Bankura district, West Bengal, India) as shown in figure 1 . Participants who gave written informed consent to participate in the study were included, and those who were absent from work on the dates of the survey were excluded.

\section{Data collection procedure and tool}

A survey was conducted with a quantitative questionnaire (available in English, Bengali and Hindi languages) in May and June 2013. The questionnaire was either selfcompleted by the participant (if literate) or completed by the fieldworker (for illiterate participants). In the latter case, each question was shown and read to the participant who was asked to say and point out the answer. Each session lasted for about $30 \mathrm{~min}$ and was completed in one sitting. Data were entered on the day of collection.

Section I of the questionnaire included the following variables: age (in years), sex, mother tongue (proxy measures for local ethnic origin, culture and lifestyle), religion, social caste (general or scheduled caste (SC)/ scheduled tribe (ST)/other backward class $(\mathrm{OBC})$ ), marriage, education (literate or illiterate), work type (non-manual or manual), working hours per day (8 $(\text { normal })^{11}$ or more than 8$)$, salary per month (5395 Indian rupees (INR: minimum monthly wage of an unskilled worker) ${ }^{11}$ or more, or less than 5395 INR), total duration of work in this type of factory (proxy measure for exposure time, in years), smoking, smokeless tobacco intake, alcohol drinking, house type (pucca/semipucca (at least some high-quality construction materials such as bricks, tiles, cement and concrete) or kachcha (low-quality construction materials such as mud and thatch)), ${ }^{12}$ people living in a room (less than 3 , or 3 or more to indicate crowding), ${ }^{12}$ pet animal at home, domestic cooking fuel (cleaner fuel (noncontinuous exposure to smoke: charcoal, coal/coke/ lignite, kerosene, electricity, petroleum gas and biogas) or biomass fuel (continuous exposure to smoke: wood/ crop residues and animal dung) ), ${ }^{12}$ separate room as kitchen at home, chimney/exhaust fan for cooking food at home, family history (presence/history of any respiratory disease in biological father/mother/siblings), personal history (presence/history of any respiratory disease) and health insurance. All the variables were dichotomous except age and total duration of work in this type of factory. Section I was designed in English, translated into Bengali and Hindi, reviewed by a local primary school teacher and pretested extensively on six local similar workers who were not involved in the study. Section II included the standardised St. George's respiratory questionnaire (SGRQ) to measure the respiratory health status. ${ }^{7} 13{ }^{14}$ This questionnaire has been widely used in the general population, different industrial workers and patients with respiratory diseases. $^{8-10} 15$ There are two parts: part 1: questions $1-8$ address participants' recollection of their symptoms over the preceding period of 3 months, and part 2: questions 9-16 address participants' current state (questions 11 and 15 measure disturbances to participants' daily physical activity, and questions 9-10, 12-14 and 16-17 cover a wide range of disturbances of psychosocial function). A total score is calculated that summarises the impact on overall respiratory health status. The score is expressed as a percentage of impairment where 100 represents the worst possible respiratory health status and 0 indicates the best possible respiratory health status. The SGRQ is available in English, Bengali and Hindi. ${ }^{73-15}$

\section{Sample size}

As this was the first study of respiratory health status of coal-based sponge iron plant workers, no information was available on which to base the sample size calculation. Instead, a web-based sample size calculator, Creative Research Systems, ${ }^{16}$ was used to calculate the sample size, using the following assumptions/information: confidence level $(95 \%)$, margin of error $(5 \%)$ and population size (total 662 coal-based sponge iron plant workers, this information was received from the factory directors in Barjora). A random sample of 258 such workers was required, assuming a response rate of $95 \%$. A numbered list of all 662 workers was created (worker 1, worker 2, worker 3 and so forth). A web-based randomiser, Research Randomizer, ${ }^{17}$ was used to generate 1 


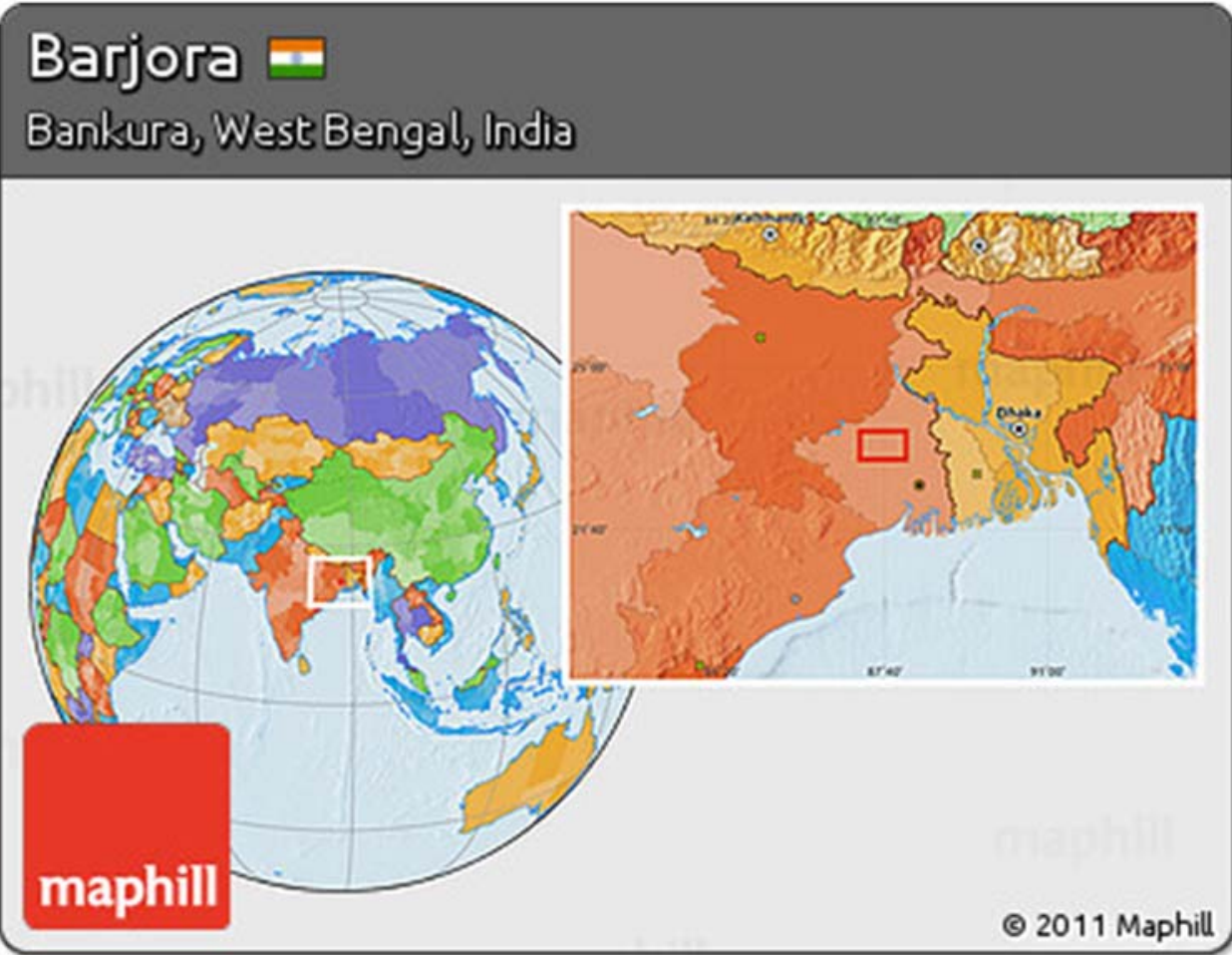

Figure 1 Location of Barjora, India.

set of 258 unique, sorted numbers with a range from 1 to 662 (representing the workers' assigned numbers).

\section{Ethics}

Information sheets and consent forms were available in English, Bengali and Hindi. ${ }^{18}$ The study objectives were explained to all the eligible participants and written informed consent was taken from those interested in participating. Illiterate participants were requested to put their left hand thumb impression on the consent form. Participants were not compelled and were free to participate in the study. They were assured regarding the anonymity, privacy, confidentiality and data protection of their information.

\section{Statistical analyses}

The SGRQ total score is a continuous variable, and was positively skewed with many zeros. Thus, the two-part model was developed, which takes advantage of the basic rule of probability and splits into two parts-frequency (ie, any worse respiratory health status and the estimate included all the participants) and severity (ie, amount of worse respiratory health status and the estimate was based on a subsample of participants with respiratory health status greater than zero). ${ }^{19} 20$ The two-part model used logit regression in the first part, and generalised linear model regression with the $\log$ link and $\gamma$ distribution in the second part. ${ }^{20}$ Both the unadjusted and adjusted (to determine independent predictors of the score) models were developed, which also included a sample with unknown values for the variables (from section I). All the section I variables were included in the adjusted model. Coefficients and their respective $95 \%$ CI were calculated. The results were considered significant when $\mathrm{p}$ values were less than or equal to 0.05 . All data were analysed using STATAV.12 for Windows software. ${ }^{21}$

\section{RESULTS}

The response rate was $100 \%$. Table 1 summarises the variables from section I. All the participants were men with a mean (SD) age of 35 (8) years. Eighty-six per cent, 96\% and $62 \%$ of participants were Bengali, Hindu and belonged to the general social caste, respectively. Eighty-six per cent and $88 \%$ of them were married and literate, respectively. Seventy-eight per cent and $74 \%$ of them were manual workers and earned less than 5395 $\mathrm{INR} /$ month, respectively. The mean (SD) total duration of work in this type of factory was 10 (14) years. Smokeless tobacco was consumed by $50 \%$ of participants. Fifty per cent of participants had a kachcha type of house, $69 \%$ of them were living in a room with three or more people, $52 \%$ of them had a pet animal at home, and $91 \%$ of them had no chimney/exhaust fan for cooking food at home. Twenty-six per cent of participants had a personal history of respiratory diseases. The mean (SD) SGRQ total score was 7.7 (14.5), the median (IQR) was 0.9 (9.0), and the observed range was $0-86.6$. The best possible SGRQ total score was reported by $46.9 \%$ of workers.

Table 2 reports the two-part model to determine factors associated with the SGRQ total score. In the unadjusted model, a higher SGRQ total score (or worse respiratory health status) was associated with cleaner 
Table 1 Section I variables

\begin{tabular}{|c|c|c|c|}
\hline \multicolumn{4}{|l|}{$n$ total $=258$} \\
\hline & n (\%) & & n (\%) \\
\hline Age & $35.4(8.2)^{\star}$ & Alcohol drinking & \\
\hline Sex & & No & $171(66.3)$ \\
\hline Male & $258(100)$ & Yes & $85(33.0)$ \\
\hline Female & 0 & Unknown & $2(0.8)$ \\
\hline Mother tongue & & House type & \\
\hline Bengali & $222(86.1)$ & Pucca/semipucca & $127(49.2)$ \\
\hline Other (Hindi/Oriya) & $29(11.2)$ & Kachcha & $129(50.0)$ \\
\hline Unknown & $7(2.7)$ & Unknown & $2(0.8)$ \\
\hline Religion & & People in a room & \\
\hline Hindu & 247 (95.7) & $<3$ & $81(31.4)$ \\
\hline Islam & $11(4.3)$ & $\geq 3$ & 177 (68.6) \\
\hline Social caste & & Pet animal & \\
\hline General & $161(62.4)$ & No & $123(47.7)$ \\
\hline SC/ST/OBC & $92(35.7)$ & Yes & 135 (52.3) \\
\hline Unknown & $5(1.9)$ & Domestic cooking fuel & \\
\hline Marital status & & Cleaner fuel & 159 (61.6) \\
\hline Yes & $221(85.7)$ & Biomass fuel & $98(38.0)$ \\
\hline No & 35 (13.5) & Other & $1(0.4)$ \\
\hline Unknown & $2(0.8)$ & Kitchen & \\
\hline Education & & Yes & $190(73.6)$ \\
\hline Literate & $226(87.6)$ & No & $67(26.0)$ \\
\hline Illiterate & $31(12.0)$ & Unknown & $1(0.4)$ \\
\hline Unknown & $1(0.4)$ & Chimney/exhaust fan & \\
\hline Work type & & Yes & $22(8.5)$ \\
\hline Non-manual & $57(22.1)$ & No & $234(90.7)$ \\
\hline Manual & $200(77.5)$ & Unknown & $2(0.8)$ \\
\hline Unknown & $1(0.4)$ & Family history & \\
\hline Working hours/day & & No & $182(70.5)$ \\
\hline 8 & $233(90.3)$ & Yes & $56(21.7)$ \\
\hline$>8$ & $23(8.9)$ & Unknown & $20(7.8)$ \\
\hline Unknown & $2(0.8)$ & Personal history & \\
\hline Salary/month & & No & $181(70.2)$ \\
\hline$\geq 5395$ INR & $68(26.4)$ & Yes & $66(25.5)$ \\
\hline$<5395$ INR & $190(73.6)$ & Unknown & $11(4.3)$ \\
\hline Total duration of work $\dagger$ & $10.0(14.1)^{\star}$ & Health insurance & \\
\hline Smoking & & No & 49 (19.0) \\
\hline No & $158(61.2)$ & Yes & 209 (81.0) \\
\hline Yes & $99(38.4)$ & & \\
\hline Unknown & $1(0.4)$ & & \\
\hline \multicolumn{4}{|l|}{ Smokeless tobacco } \\
\hline No & $128(49.6)$ & & \\
\hline Yes & $129(50.0)$ & & \\
\hline Unknown & $1(0.4)$ & & \\
\hline
\end{tabular}

domestic cooking fuel (coefficient $-0.53,95 \%$ CI -1.04 to $-0.03, \mathrm{p}=0.039)$ and personal history of any respiratory disease $(1.66,0.99$ to $2.33, \mathrm{p}<0.001)$ in case of frequency; and family history of any respiratory disease $(0.47,0.01$ to $0.94, \mathrm{p}=0.047)$ and personal history (1.14, 0.84 to $1.44, \mathrm{p}<0.001)$ in case of severity. Independent predictors of a higher SGRQ total score were cleaner domestic cooking fuel $(-0.76,-1.46$ to $-0.06, \mathrm{p}=0.034)$ and personal history $(1.76,1.04$ to $2.47, \mathrm{p}<0.001)$ in case of frequency; and family history $(0.43,0.02$ to 0.83 , $\mathrm{p}=0.039)$ and personal history $(1.19,0.83$ to 1.54 , $\mathrm{p}<0.001)$ in case of severity. McFadden's pseudo $\mathrm{R}^{2}$ value was 0.14 (for the adjusted model).

\section{DISCUSSION}

The study findings are compared with studies conducted among the general population and other industrial workers in various countries, ${ }^{8-10}$ as respiratory health status studies conducted among coal-based sponge iron 
命

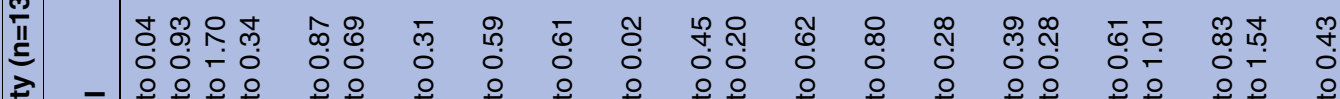

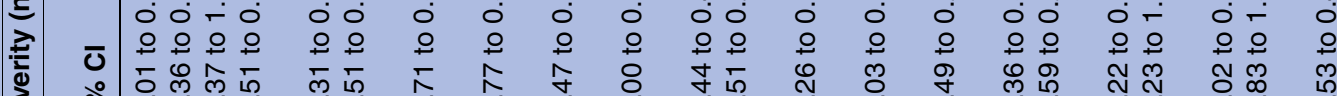

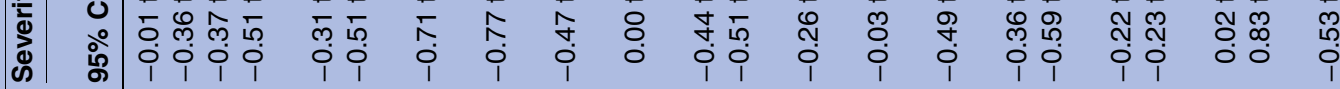

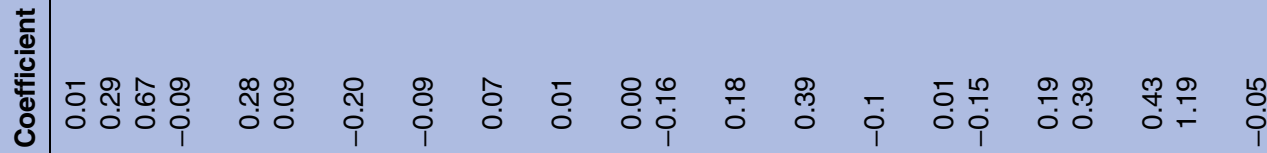

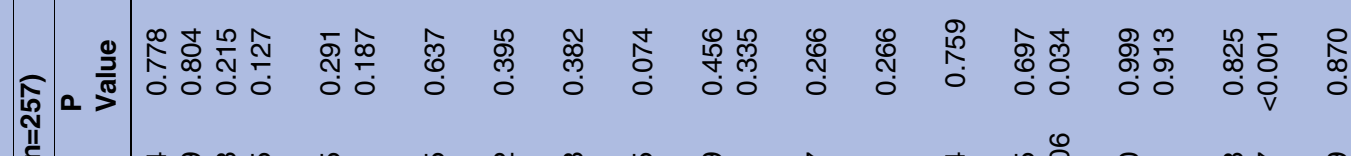
光

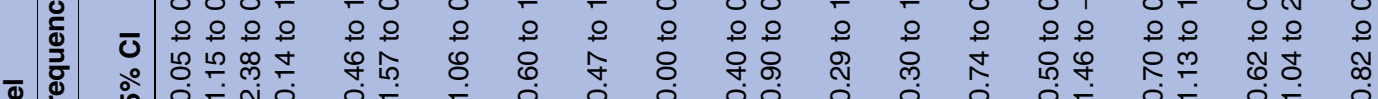

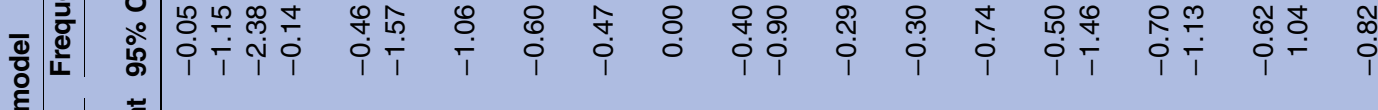

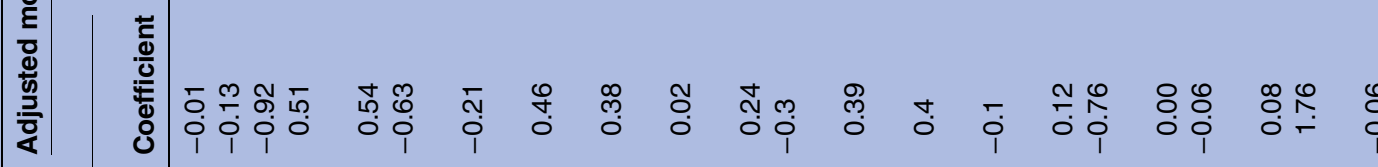
உ ஊ

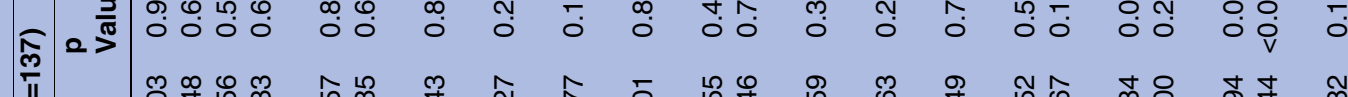

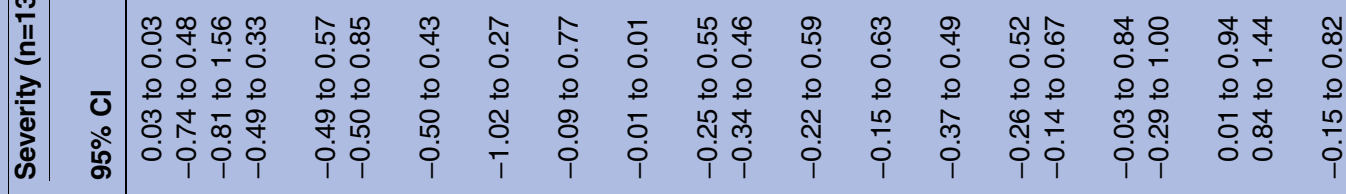

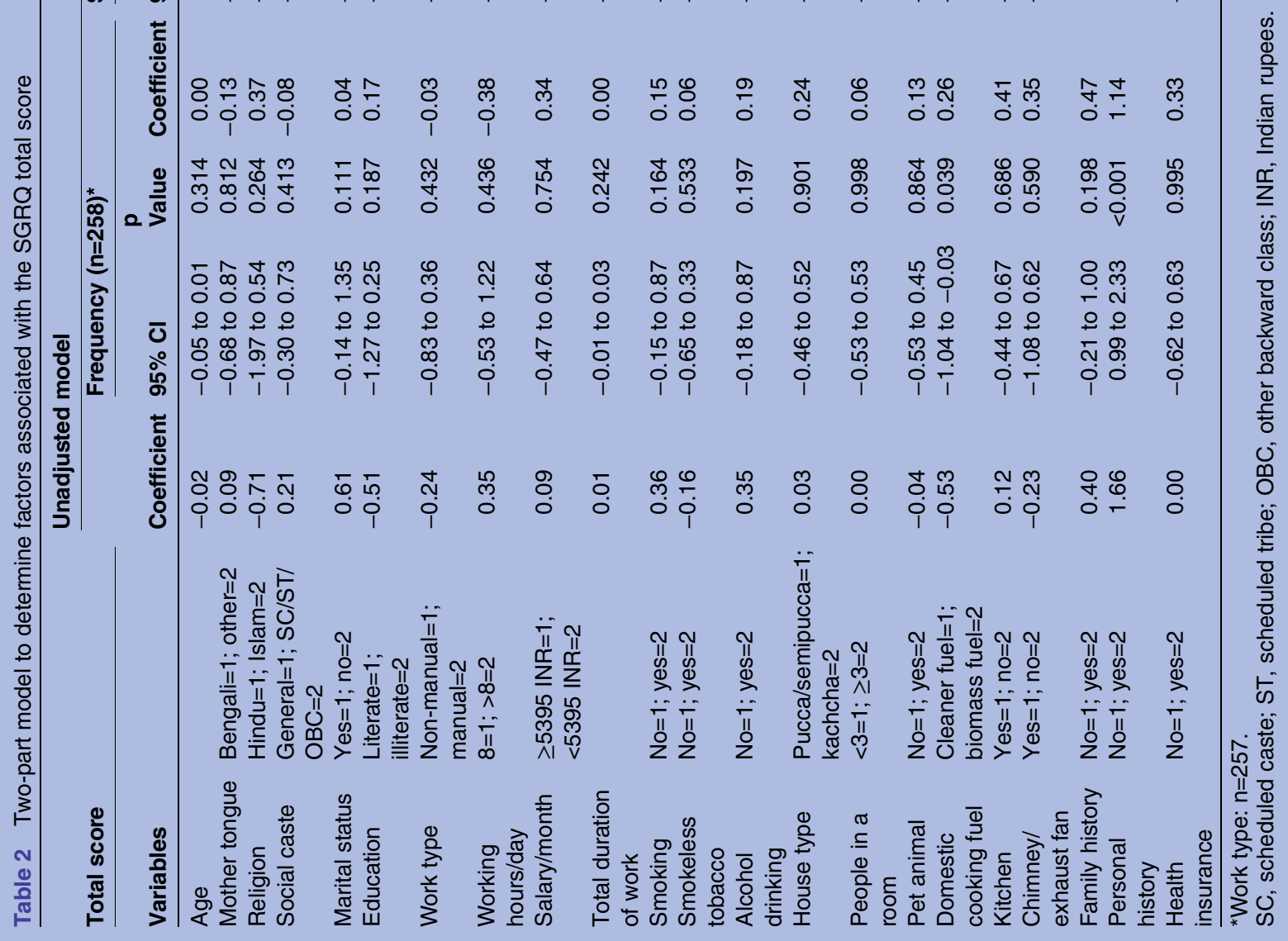


plant workers are lacking. In our study, the SGRQ total score distribution was positively skewed-the mean (SD) was 7.7 (14.5) and the median (IQR) was 0.9 (9.0). This was also found in the Japanese industrial workers study (aged above 40 years) - the mean (SD) score was 6.4 (5.7), and the median score was $5.3 .^{10}$ The mean (SD) score was 8.4 (11.3) and 7 (7) in studies conducted among the Spanish general population aged 40-69 years and among British people aged 17-80 years with no respiratory diseases, respectively. ${ }^{8}{ }^{9}$ Undesirably, the maximum score was high (observed range 0-86.6) in our study. This was consistent with the Spanish study (observed range 0-83.4). ${ }^{9}$ The maximum score was better among the Japanese industrial workers (51.5). ${ }^{10}$ The best possible respiratory health status was reported by only $46.9 \%$ of workers. In the Spanish study, a lower percentage of participants $(21.1 \%)$ reported the best possible respiratory health status. This could be due to the fact that the Spanish study knowingly included a high proportion of individuals with respiratory diseases and they were comparatively much older (aged 4069 years) ${ }^{9}$ In the Japanese study, $8.9 \%$ of participants reported the best possible respiratory health status, and again the participants were comparatively much older (aged above 40 years). ${ }^{10}$ Although the SGRQ is constructed in such a way that a score of zero indicates the best possible respiratory health status, even people who do not suffer from respiratory diseases will very rarely score the minimum on all the items. ${ }^{9}{ }^{10}$ In addition, it is assumed that the SGRQ measures specifically the respiratory health status impact of respiratory diseases; however, it may also reflect the impact of other comorbidities. ${ }^{22}$ Psychological factors (such as anxiety and depression) negatively influence the respiratory health status, and previous studies have shown a significant association between psychological factors and the SGRQ score in people with respiratory diseases. ${ }^{23} 24$

In the unadjusted model, a higher SGRQ total score (or worse respiratory health status) was associated with cleaner domestic cooking fuel and personal history of any respiratory disease in case of frequency; and family history of any respiratory disease and personal history in case of severity. Independent predictors of worse respiratory health status were the same. Considering the points that McFadden's pseudo $R^{2}$ tends to be smaller than $R^{2}$ and values from 0.20 to 0.40 indicate an excellent model fit, ${ }^{25}$ McFadden's pseudo $\mathrm{R}^{2}$ value of 0.14 in our study indicates a satisfactory model fit. The Spanish general population study found older age, lower education and manual work to be associated with worse respiratory health status (in unadjusted models). After adjustment, this study found respiratory diseases, smoking, older age and lower education to be associated with worse respiratory health status. ${ }^{9}$ In our study, participants with a personal history had worse respiratory health status. This is consistent with another study conducted among the same population, where participants with a personal history had worse health-related quality-of-life (measured using the EuroQol-visual analogue scale (EQ-VAS)) as compared with those with no such issue. ${ }^{26}$ This is also consistent with the Japanese industrial workers study where they found an association with chronic obstructive pulmonary disease. ${ }^{10}$ Our study showed the significance of personal history and of family history in someone's respiratory health status. We found an association between cleaner domestic cooking fuel and worse respiratory health status. This association is quite conflicting, and one would expect the association between biomass domestic cooking fuel and worse respiratory health status. It is possible that this finding was the result of other confounding factors not adjusted for in the model. This finding deserves further examination.

This study has a number of strengths and weaknesses. To the best of our knowledge, this is the first study to explore respiratory health status of coal-based sponge iron plant workers. All the workers who were approached to participate in the study responded (100\% response rate and thus no non-respondents). This indicates that the data collection methodology was appropriate and there is more certainty in the study findings (ie, it is more likely that the results are representative of the population). In terms of generalisability, the study findings could be valid in settings with similar populations and healthcare systems (such as in other South-Asian countries). The standard steps in questionnaire development (design, translation and pretesting) were followed to ensure the validity and reliability of the questionnaire (section I). Respiratory health status measurement is subjective to participants, and thus a valid and reliable tool (SGRQ in English, Bengali and Hindi) was used. The fieldworkers used a standardised protocol for data collection. The fieldworkers and the participants belonged to the same culture, which minimised the scope for cultural bias in the study. Missing data could lead to bias, but it was extremely low in this study. The analyses included a sample with missing values for the variables. Participants who were absent from work on the dates of the survey were excluded, and this absence from work could be due to poor respiratory health status, which could have underestimated the worse respiratory health status. The response of participants could have been influenced by the context, and individual and contextual psychosocial work factors are known to influence the perception of the environment at work. ${ }^{27} 28$ Most of the data were self-reported, and recall error could have been a problem. Medical records might be a more reliable measure (for the presence/ history of any respiratory disease), but these were not available/accessible in the study area. Lung function or other diagnostic tests could have been used, but the aim of the study was to explore workers' perception of respiratory health (respiratory health status) and not to diagnose any disease condition. However, these tests could be used in future studies, which would cross-check our study findings and would provide a complete picture of the scenario. The aim of the study was to 
explore these workers' respiratory health status, and there was no control group in the study. Similar research needs to be conducted among coal-based sponge iron plant employees working in other parts of India and other countries to enhance the generalisability of our study results. As this was a cross-sectional study, it was not possible to determine the causal association between different variables and respiratory health status. A longterm, longitudinal study should be conducted among these coal-based sponge iron factory workers to assess the impact of various factors (these as well as other potential factors) on their respiratory health status. A good example would be to have a cohort study comparing coal-based sponge iron factory workers with other types of factory workers (healthy worker effect), rather than with the general population.

In conclusion, less than half of the coal-based sponge iron plant workers in Barjora have the best possible respiratory health status. The predictors of worse respiratory health status were identified. The study findings could be taken into consideration in future interventional studies aimed at improving the respiratory health status of these workers.

Acknowledgements The authors thank the funding agency, Suresh Chandra Chattopadhyay, the fieldworkers, Barjora BDO, the factory directors and the participants.

Contributors KC designed the study. KC, CC and EK conducted the study. KC wrote the first draft of the manuscript. All authors revised for important intellectual content and approved the final manuscript.

Funding This study was funded by a grant from the Blacksmith Institute, USA.

Competing interests None.

Patient consent Obtained.

Ethics approval Approval was received from the Barjora Block Development Office Committee (the committee was based on the Indian Council of Medical Research Ethical Guidelines for Biomedical Research on Human Participants, 2006).

Provenance and peer review Not commissioned; externally peer reviewed.

Data sharing statement No additional data are available.

Open Access This is an Open Access article distributed in accordance with the Creative Commons Attribution Non Commercial (CC BY-NC 4.0) license, which permits others to distribute, remix, adapt, build upon this work noncommercially, and license their derivative works on different terms, provided the original work is properly cited and the use is non-commercial. See: http:// creativecommons.org/licenses/by-nc/4.0/

\section{REFERENCES}

1. Patra HS, Sahoo B, Mishra BK. Status of sponge iron plants in Orissa. Bhubaneswar, India: Vasundhara, 2012.

2. Centre for Science and Environment (CSE). Sponge iron industry: the regulatory challenge. New Delhi, India: CSE, 2011.
3. Chatterjee S. Source, dispersal and impacts of airborne pollutants: a case study of Mangalpur industrial complex, Raniganj. J Hum Ecol 2011;35:195-201.

4. Cerana Foundation. Risk appraisal study: sponge iron plants, Raigarh district. Hyderabad, India: Cerana Foundation, 2006.

5. Curtis JR, Deyo RA, Hudson LD. Health-related quality of life among patients with chronic obstructive pulmonary disease. Thorax 1994;49:162-70.

6. World Health Organization (WHO). International classification of functioning, disability and health: ICF. Geneva, Switzerland: WHO, 2001

7. Jones PW. Issues concerning health-related quality of life in COPD. Chest 1995;107(5 Suppl):187-93.

8. Spencer S, Calverley PM, Sherwood Burge P, et al. Health status deterioration in patients with chronic obstructive pulmonary disease. Am J Respir Crit Care Med 2001;163:122-8.

9. Ferrer M, Villasante C, Alonso J, et al. Interpretation of quality of life scores from the St. George's respiratory questionnaire. Eur Respir J 2002;19:405-13.

10. Nishimura K, Mitsuma S, Kobayashi A, et al. COPD and diseasespecific health status in a working population. Respir Res 2013;14:61.

11. Office of the Labour Commissioner (OLC), Government of West Bengal. Monthly minimum rates of wages. Kolkata, India: OLC 2013.

12. Mishra VK, Retherford RD, Smith KR. Biomass cooking fuels and prevalence of blindness in India. J Environ Med 1999;1:189-99.

13. Jones PW, Quirk FH, Baveystock CM. The St George's respiratory questionnaire. Respir Med 1991;85(Suppl B):25-31.

14. Jones PW, Quirk FH, Baveystock CM, et al. A self-complete measure for chronic airflow limitation: the St George's respiratory questionnaire. Am Rev Respir Dis 1992;145:1321-7.

15. Jones PW, Forde Y. St. George's respiratory questionnaire manual (version 2.3). London, UK: St. George's, University of London, 2009.

16. Creative Research Systems (CRS). Sample size calculator. California: 2012. http://www.surveysystem.com/sscalc.htm (accessed 1 May 2013).

17. Urbaniak GC, Plous S. Research randomizer (version 4.0) [computer software]. Social Psychology Network. 2013. http://www. randomizer.org/form.htm (accessed 1 May 2013).

18. Indian Council of Medical Research (ICMR). ICMR ethical guidelines for biomedical research on human participants. Delhi, India: 2006.

19. Lachenbruch PA. Analysis of data with excess zeros. Stat Methods Med Res 2002;11:297-302.

20. Belotti F, Deb P, Manning WG, et al. tpm: estimating two-part models. Stata J 2012;55:1-13.

21. STATACorp. STATA statistical software: release 12. College Station, TX: 2011.

22. Ferrer $\mathrm{M}$, Alonso J, Morera J, et al. Chronic obstructive pulmonary disease stage and health-related quality of life. The Quality of Life of Chronic Obstructive Pulmonary Disease Study Group. Ann Intern Med 1997:127:1072-9.

23. Dyer CA, Hill SL, Stockley RA, et al. Quality of life in elderly subjects with a diagnostic label of asthma from general practice registers. Eur Respir J 1999;14:39-45.

24. Balcells E, Gea J, Ferrer J, et al. Factors affecting the relationship between psychological status and quality of life in COPD patients. Health Qual Life Outcomes 2010;8:108.

25. Hensher DA, Stopher PR. Behavioural travel modelling. London, UK Croom Helm, 1979.

26. Chattopadhyay K, Chattopadhyay C, Kaltenthaler E. Health-related quality-of-life of coal-based sponge iron plant workers in Barjora, India: a cross-sectional study. BMJ Open 2014;4:e006047.

27. Magnavita N. Work-related symptoms in indoor environments: a puzzling problem for the occupational physician. Int Arch Occup Environ Health 2015;88:185-96.

28. Brauer $\mathrm{C}$, Mikkelsen $\mathrm{S}$. The influence of individual and contextual psychosocial work factors on the perception of the indoor environment at work: a multilevel analysis. Int Arch Occup Environ Health 2010;83:639-51. 